\title{
Recent Advances in Plant Chemical Biology of Jasmonates
}

\author{
Minoru Ueda ${ }^{1,2, *(\mathbb{D}}$, Takuya Kaji ${ }^{1} \mathbb{D}$ and Wataru Kozaki ${ }^{1}$ \\ 1 Department of Chemistry, Graduate School of Science, Tohoku University, Sendai 980-8578, Japan; \\ takuya.kaji.c6@tohoku.ac.jp (T.K.); wataru.kozaki.t6@dc.tohoku.ac.jp (W.K.) \\ 2 Department of Molecular and Chemical Life Sciences, Graduate School of Life Sciences, Tohoku University, \\ Sendai 980-8578, Japan \\ * Correspondence: minoru.ueda.d2@tohoku.ac.jp; Tel.: +81-22-795-6553
}

Received: 30 December 2019; Accepted: 6 February 2020; Published: 7 February 2020

check for updates

\begin{abstract}
Lipid-derived plant hormone jasmonates are implicated in plant growth, reproductive performance, senescence, secondary metabolite productions, and defense against both necrotrophic pathogens and feeding insects. A major jasmonate is (+)-7-iso-jasmonoyl-L-isoleucine (JA-Ile), which is perceived by the unique COI1-JAZ coreceptor system. Recent advances in plant chemical biology have greatly informed the bioscience of jasmonate, including the development of chemical tools such as the antagonist COR-MO; the agonist NOPh; and newly developed jasmonates, including JA-Ile-macrolactone and 12-OH-JA-Ile. This review article summarizes the current status of plant chemical biology as it pertains to jasmonates, and offers some perspectives for the future.
\end{abstract}

Keywords: jasmonates; COI1-JAZ; agonist; antagonist

\section{Introduction}

Plant hormones are signal molecules present in low concentrations in plants that control all aspects of plant growth and development. Historically, plant hormones have been identified by conventional chemical isolation techniques combined with plant phenotype assays. However, postgenomic biology has enabled the genetic identification of previously unknown plant hormones, such as the carotenoid-derived hormone strigolactone, which was discovered by a combined biosynthesis/genetic analysis approach [1,2], and some peptide hormones, by genetic analyses of the Arabidopsis genome [3].

Jasmonic acid (JA, Figure 1A) was first identified as a volatile component of jasmine in 1962 [4], and has been considered a plant hormone since the discovery that it causes a variety of biological responses in plants, including defense responses to attack by herbivorous insects or necrotrophic pathogens, biological responses to injury, the enhanced production of secondary metabolites, male sterility, sex-determination of plants, and growth inhibition [5-10]. The unique coreceptor system of jasmonate was disclosed by Solano's [11], Howe's [12], and Farmer's groups [13], and found to entail protein-protein interactions between F-box protein CORONATINE INSENSITIVE 1 (COI1) and repressor protein JASMONATE ZIM-DOMAIN (JAZ) to form the COI1-JAZ coreceptor (Figure 1B). Subsequent degradation of JAZ repressor through a ubiquitination-guided 26S-proteasome mechanism activates the expression of the downstream gene, which is repressed by JAZ repressor. More recently, however, genetic studies concluded that (+)-7-iso-jasmonoyl-L-isoleucine (JA-Ile) is in fact the genuine plant hormone to which JA is merely a precursor: the JAR1 enzyme belonging to GH3 enzyme family which conjugates amino acids to diverse acyl acids is indispensable for activating the jasmonate response [14], and the jasmonate receptor COI1-JAZ has a strong affinity for JA-Ile but not JA [12]. Additionally, stereochemical studies concluded that the biosynthetic (7S, 3R)-JA-Ile (also known as $(+)-7-i s o)$ isomer is the genuine bioactive form that is easily epimerized to give a naturally occurring 
mixture of the thermodynamically stable $(7 R, 3 R)$-form and biologically active $(7 S, 3 R)$-form in a ratio of 95:5 (Figure 1A) [15].

A<smiles>CC=CC1C(=O)CCCC1C(C)C</smiles>

Jasmonic acid (JA)

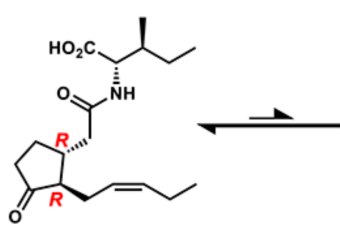

Inactive form (7R, 3R)-JA-L-Ile (95\%)

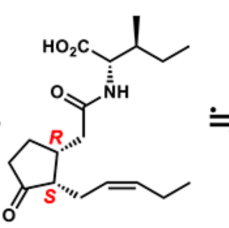

Active form (7S, 3R)-JA-L-Ile (JA-Ile) $(5 \%)$

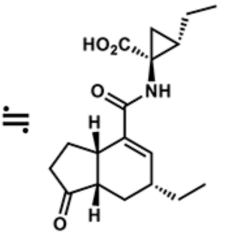

Coronatine (COR)

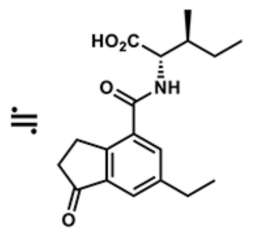

Coronalone

B

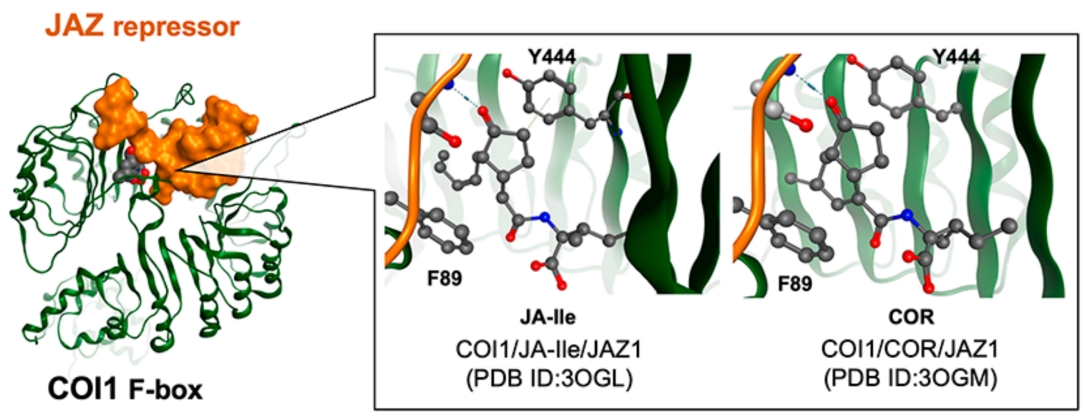

Figure 1. Jasmonic acid (JA) ligands and COI1-JAZ coreceptor. (A) Structures of JA, active/inactive form of 7-iso-jasmonoyl-L-isoleucine (JA-Ile), coronatine (COR), and coronalone and (B) comparison of the COI1 (green)/JA-Ile/JAZ1 (orange) complex (left, PDB:3OGL) and the COI1/COR/JAZ1 complex (right, PDB:3OGM) at the ligand binding pocket. ${ }^{89} \mathrm{Phe}$ and ${ }^{444} \mathrm{Tyr}$ sidechains of COI1 are highlighted in ball-and-stick.

Recent advances in plant hormone biology [16], especially a vastly improved understanding of the unique coreceptor system [17], has enabled the development of chemical tools, including antagonists and agonists. Such tools are needed to probe the precise mechanistic pathways by which plants develop. The first of these was auxinole, an antagonist of auxin receptor TIR1/IAA, which paved the way for agonist/antagonist rational design (Figure 2A) [18,19]. Chemical tools have greatly contributed to our understanding and ability to control the signaling pathway of plant hormones. In this review article, we will summarize the advances in the plant chemical biology on jasmonates, and offer some perspectives for the future.

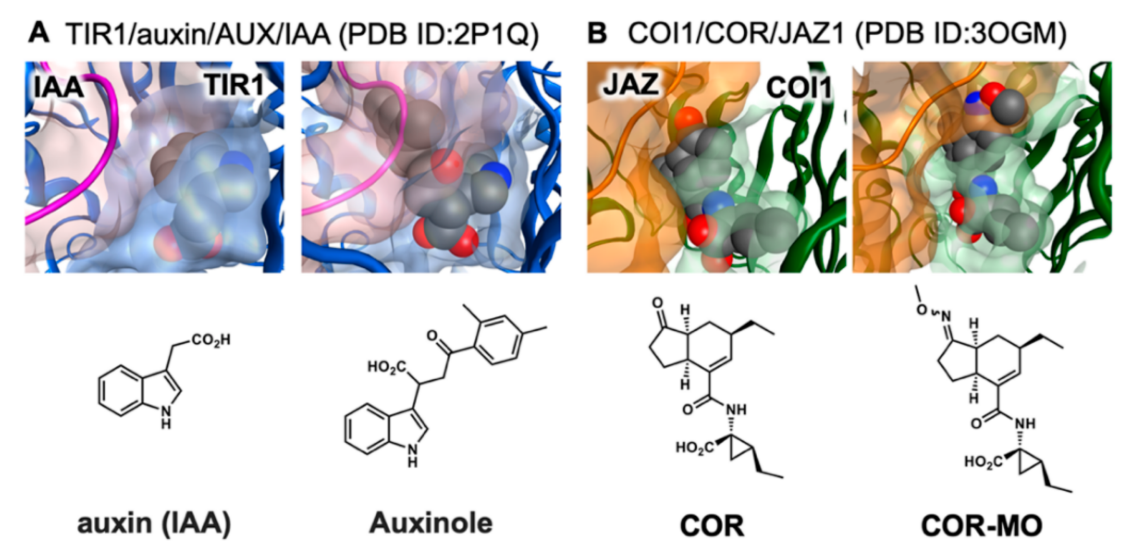

Figure 2. Cont. 


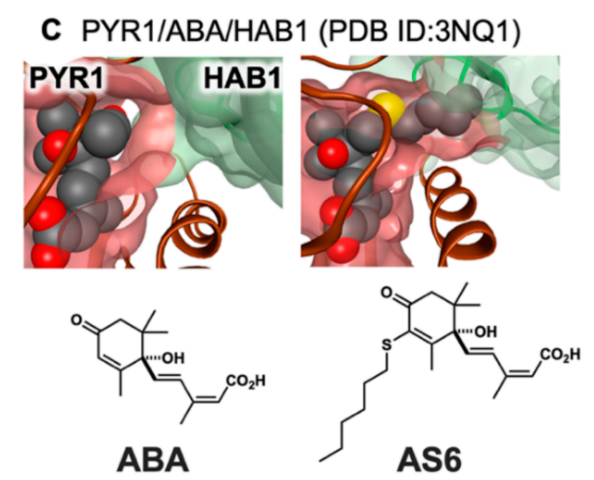

Figure 2. Structure-guided antagonist design. (A) Auxinole is superimposed onto TIR1 (blue)-AUX/IAA (purple) coreceptor (PDB:2P1Q), (B) COR-MO is superimposed onto COI1 (green)-JAZ1 (orange) coreceptor (PDB:3OGM), and (C) AS6 is superimposed for PYR1 (brown)-HAB1 (green) coreceptor (PDB: 3QN1 and 3WG8). The structures were modeled and rendered by MOE (Molecular Operating Environment, 2011.10; Chemical Computing Group Inc., Montreal, QC, Canada, 2011).

\section{The Conventional Chemical Tools for Jasmonate Bioscience}

The most important chemical tool for the study of jasmonate bioscience is the phytotoxin coronatine (COR, Figure 1A), produced by Pseudomonas syringae and first identified in 1977 [20]. COR is widely known as "super strong JA", having a similar bioactivity profile to JA but an enhanced potency [21]. This enhanced potency can be understood in terms of the structure of COR, which incorporates a sTable 5-6-conjugated ring system mimicking the structure of JA-Ile, but one that cannot isomerize into (7R, $3 R$ )-form; the analogous isomerization of (7S, 3R)-JA-Ile into the (7R, 3R)-form leads to loss of potency. In addition, the crystal structure of COI1-COR-JAZ1 complex suggests a strong hydrophobic interaction between the 5-6-conjugated ring system of COR and ${ }^{89} \mathrm{Phe}$ and ${ }^{444} \mathrm{Tyr}$ of COI1 (Figure 1B) [22]. COR is widely used in JA bioscience instead of JA because of the chemical stability of bioactive $(7 R, 3 R)$-form, and its most important contribution so far has been the development of the coil-1 mutant, which incorporates a mutation in gene encoding the COI1 protein (a component of COI1-JAZ coreceptor) and is insensitive to COR [23]. Today, COR is considered as a structural and functional mimic of JA-Ile, and has been accessible in multigram quantities and good optical purity since the landmark work of Watson's and Ueda's groups [24-26].

One alternative to COR is coronalon, which causes JA-like responses in plants, such as volatile production and defense response against insect attack $[27,28]$. Coronalon is a 6-ethyl indanyl isoleucine conjugate, the synthesis of which is relatively straightforward (Figure 1A). Both coronalon and COR cause many JA responses in a variety of plants, such as Arabidopsis, lima bean, soy bean, and tobacco.

\section{Development of Coronatine-Based Antagonist/Agonists of Jasmonate Signaling}

In general, a complete understanding of plant hormone signaling is difficult due to significant genetic redundancy of the receptor encoding genes in the plant genome [29], which precludes the exact clarification of the function of each subtype [30]. Functional redundancy among the members of such a multigene family will often hinder the genetic analysis of the contribution of individual genes using a reverse genetics strategy, because genetic knock-out of one redundant gene will be compensated for by other genes belonging to the same gene family. For example, one COI1 gene and 13 JAZ genes on COI1-JAZ coreceptor of jasmonate [29], and six TIR1/AFB genes and 29Aux/IAA genes on TIR1/AFB-Aux/IAA coreceptor of auxin, are encoded in the Arabidopsis genome (Figure 3A). The functional $J A Z$ genes are $J A Z 1 / 2 / 3 / 4 / 5 / 6 / 9 / 10 / 11 / 12$, because $J A Z 7 / 8 / 13$ lack the canonical LPIARR motif in the degron necessary for the formation of COI1-JAZ coreceptor [31-35].

Chemical biology using receptor antagonists/agonists constitutes a promising solution to this problem. A general antagonist can disable all redundant signaling networks at once, and a specific agonist can trigger signaling from an otherwise redundant signaling network. However, such chemical 
biology studies are designed on structural information. In the context of COI1-JAZ antagonist development, Zheng's group disclosed the crystal structure of COI1-JA-Ile/COR-JAZ1 ternary complex (Figure 1B) [22], which turned out to be very close to that of auxin receptor TIR1-IAA [36]. Interestingly, the ketone moiety of JA-Ile/COR was found to play an important role in the hydrogen bonding that causes COI1 and JAZ to interact (Figure 1B). Solano' s group developed a rationally designed antagonist of the COI1-JAZ coreceptor system [37]—to date the only antagonist of the COI1-JAZ coreceptor-based on this important insight. The antagonist, COR-MO, is a chemically modified COR bearing a bulky methyl oxime group that protrudes from the ligand-binding pocket of COI 1 and serves to impede the access of the JAZ protein, thereby inhibiting the formation of the COI1-JAZ coreceptor (Figure 2B). COR-MO effectively antagonizes the formation of COI1-JAZ complex caused by JA-Ile, and also inhibits in planta biological responses known to be caused by JA-Ile including inhibition of root elongation, anthocyanin accumulation, and the defense response against infection by necrotrophic pathogens. Previously reported antagonists of other plant hormones, such as auxinole for auxin receptor (Figure 2A) [18], and AS6 of abscisic acid (ABA) receptor (Figure 2C) [38], were also designed by inhibition of protein-protein interactions by chemical modification of plant hormone structure. The bulky alkyl chain introduced in auxinol interferes with access of Aux/IAA to the TIR1-auxinol complex, and the bulky C6-alkyl chain in AS6 interferes with the access of HAB1 to the PYR1-AS6 complex.

In contrast, progress towards the development of COI1-JAZ agonists has been much slower. One possible approach is the use of 'biased' agonists, which have selective affinity for the 10 genetically redundant JAZ and can be a powerful tool for the understanding of such a genetically redundant system. However, there are few successful examples of 'biased' plant hormone receptor agonists. Cutler's group successfully developed the ABA receptor agonists [39] pyrabactin [40,41], quinabactin [42], cyanabactin [43], and opabactin [44], which were identified by random screening of a large-scale chemical library, and exhibited remarkable selectivity among 15 ABA receptor subtypes. The same method also resulted in the identification of SPL7, a femtomolar agonist selective for a strigolactone receptor ShHTL7 involved in the seed germination of parasitic plant Striga hermonthica [45].

For years, the chemical screening approach was considered the only way to develop plant hormone receptors agonists, partly because no paradigm with which to accomplish their rational design existed. However, in pioneering work, Ueda's group succeeded in the rational design of subtype-selective agonists for the COI1-JAZ coreceptor system by using unique stereochemistry-based tuning of subtype selectivity (Figure 3B) [46]. COR as well as JA-Ile could induce protein-protein interaction (PPI) between COI1 and 10 of 13 JAZs; this multiple ligand ability of COR was attributed to the exquisite 3D structure of COR, which enabled the formation of hydrogen bond networks in all 10 possible combinations of COI1 and JAZ (Figure 3A). The slight modification of this exquisite 3D structure enabled the fine-tuning of the hydrogen bond-network (Figure 3B). The structurally modified COR could not retain a hydrogen bond-network in some of the COI1-JAZ combinations, introducing bias into its agonistic properties. Four stereochemical hybrid isomers of COR were synthesized as modified CORs, each of which could hold the same size-exclusion volume as that of original COR and could be accommodated into the small space between interreacting COI1 and JAZ. As expected, one of the four stereochemical isomers was found to have moderate selectivity (5/10) for 10 possible combinations of COI1 and JAZ (Figure 3C), and was improved using an in silico molecular docking strategy, resulting in NOPh that had high selectivity for 2/10 possible COI1-JAZ combinations (Figure 3C). NOPh is a phenyloxime derivative of COR stereoisomer and cause PPI between COI1 and JAZ9/10. NOPh-treated Arabidopsis showed a moderate defense response against infection by necrotrophic pathogens, without causing growth inhibition. The mode of action of NOPh was carefully examined through genetic studies, and concluded to entail selective activation of the ERF-ORA branch, one of the two major branches of jasmonate signaling pathway, through binding with COI1-JAZ9 coreceptor pair (Figure 3D). This result suggested the possible significance of chemical tools for further studies on the function of genetically redundant plant hormone receptors, and demonstrated that the transient degradation of an individual JAZ subtype might circumvent the functional compensation by other members in 
multigene family, which occurs in mutant plant during the development [30]. The use of a chemical tool enables the dissection of genetically redundant COI1-JAZ coreceptor function to disclose the contribution of individual subtype. Recently, Xie's groups suggested that the affinity between COI1 and JA-Ile has been underestimated based on the observation that JA-Ile is first perceived by COI1 and the complex subsequently binds JAZs to cause a jasmonate response, and therefore the genuine receptors for JA-Ile may be COI1 $[47,48]$. This result may lead to new insight for the molecular design of improved agonist/antagonist of COI1-JAZ coreceptor system.

A

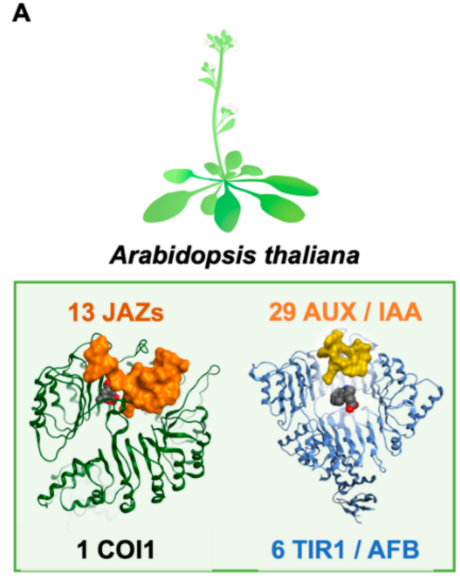

C
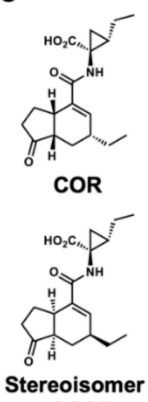

of COR

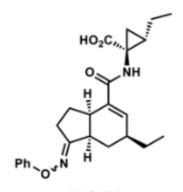

NOPh
B

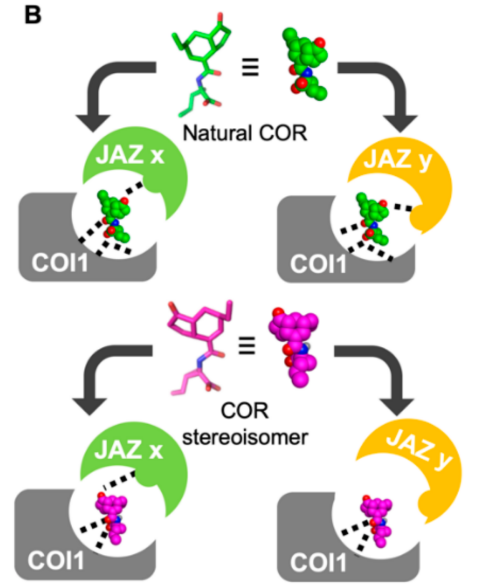

D

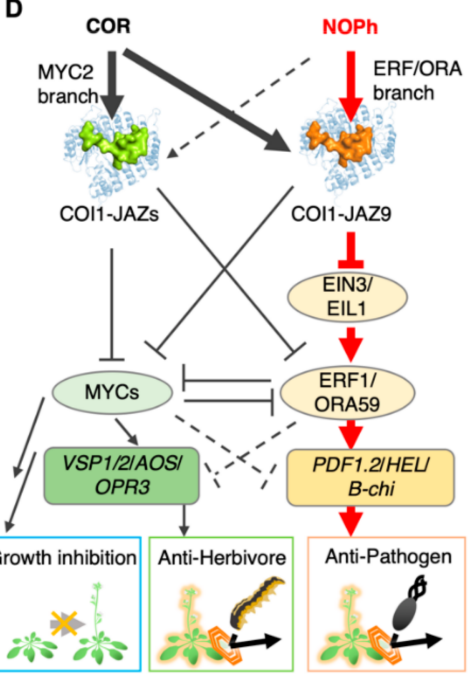

Figure 3. Stereochemistry-based tuning of JASMONATE ZIM-DOMAIN (JAZ) subtype selectivity. (A) Redundancy in plant hormone coreceptor complex; (B) schematic view of stereoisomer-based tuning of JAZ subtype selectivity; (C) observed JAZ subtype selectivity for one stereoisomer of COR and NOPh; and (D) overview of the mode of action of NOPh, a selective activation of ERF-ORA branch signaling pathway [49].

Dissection of the genetic redundancy of COI1-JAZ coreceptors has also been attempted by genetic approaches. Howe's group elaborated the jazD mutant in which 10 JAZ genes (JAZ1-7, -9, -10, and -13) are impaired [50]. Most jasmonate responses, such as upregulated defense response against necrotrophic pathogens and feeding insects, growth inhibition, poor reproductive performance, and secondary metabolite production, are observed in jazD through the activation of jasmonate signaling pathway. jazD can be an important background in which a $J A Z$ subtype is knocked-in to examine the responsible phenotype. Solano's group use Marchantia polymorpha L. instead of Arabidopsis [51,52]. No genetic redundancy is observed in the jasmonate signaling of $M$. polymorpha, because single MpCOI1 
and $M p \mathrm{JAZ}$ are encoded in the genome. Chemical biology using chemicals will be complementary to these two promising genetic approaches.

\section{Protein Engineering on Ligand-Receptor Interaction in Plants}

A particularly promising strategy for the study of plant hormone signaling is the combination of chemistry and protein engineering (Figure 4). For example, He's group reported the breakthrough achievement of controlling the ligand selectivity of the COI1-JAZ coreceptor system [53]. This was accomplished by examination of the crystal structure of COI1-JA-Ile/COR-JAZ1, which led to the conclusion that perturbation of the shape of the ligand-binding pocket of COI1 by introduction of a point mutation $\left({ }^{384} \mathrm{Ala}\right.$ to ${ }^{384}$ Val to give COI $\left.{ }^{\mathrm{A} 384 \mathrm{~V}}\right)$ would allow accommodation of JA-Ile, without binding to COR (Figure 4A). The flexible side chain of JA-Ile can move to avoid streric hindrance in the biding pocket. The transgenic Arabidopsis plant engineered to express COI1 ${ }^{\mathrm{A} 384 \mathrm{~V}}$ instead of wild-type COI1 was found to be insensitive to phytotoxin COR, and exhibited significantly increased resistance to pathogenic infection compared with wild-type plants. This result demonstrated that protein engineering techniques can affect the ligand selectivity of the plant hormone receptor. A similar strategy was also reposted by Cutler's group [54], who modified the ligand-binding pocket of PYR1 to accommodate mandipropamid, a commercially available agrochemical. Transgenic Arabidopsis expressing engineered PYR1 exhibited upregulated drought tolerance (Figure 4B). In 2017, Torii and Itami's group also applied the bump-and-hole approach [55] to auxin receptor TIR1-Aux/IAA (Figure 4C) [56]. A selective pair of bumped-auxin and holed-TIR1 was developed; among the six subtypes of TIR1/AFB, only the holed TIR1 could bind bumped-auxin to cause PPI with Aux/IAAs, although no selectivity for the possible 29 subtypes of Aux/IAA repressors was observed. Focusing on the close relationship between TIR1/AFB-Aux/IAA and COI1-JAZ receptor systems, this achievement can be also applied to jasmonate signaling to enable the selective activation of one COI1-JAZ pair among possible 10 pairs. For this purpose, a new strategy of bump-and-hole for the repressor JAZs, which correspond to Aux/IAA in auxin receptor, is necessary.

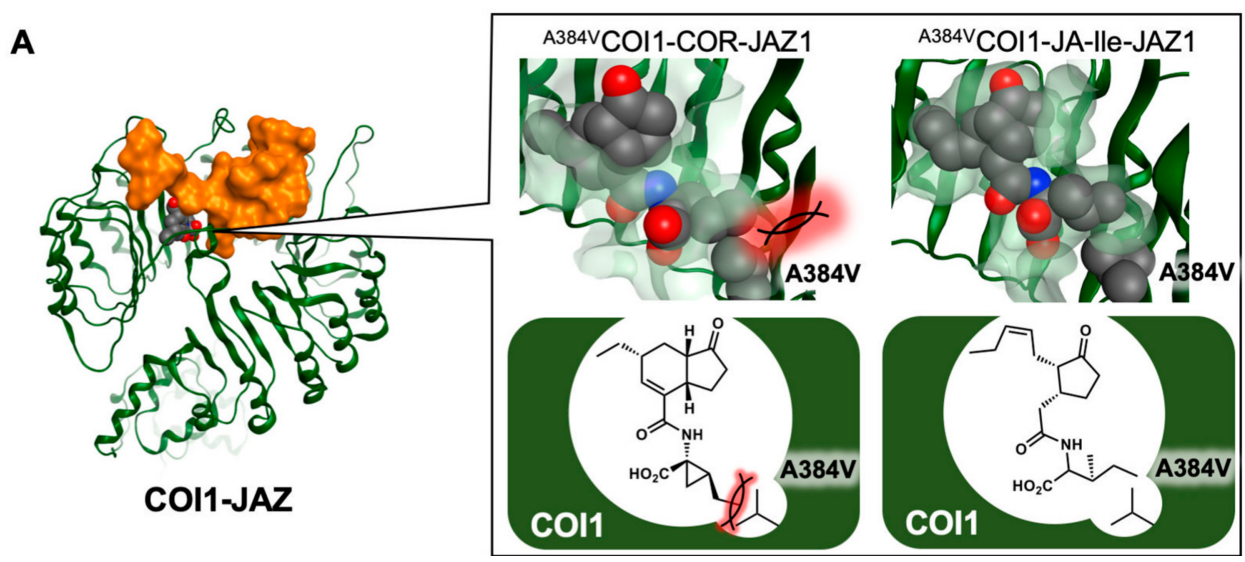

Figure 4. Cont. 


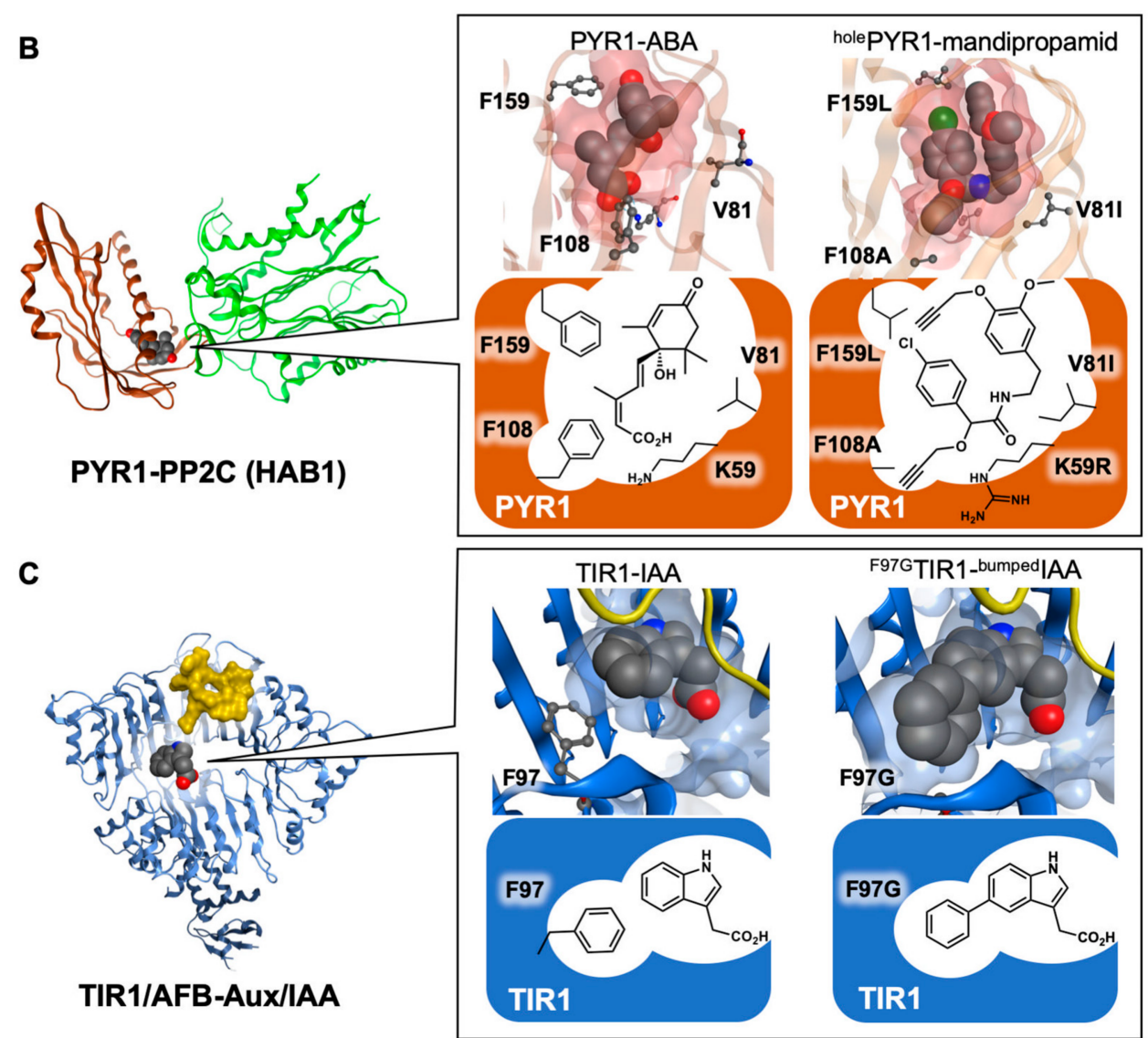

Figure 4. Protein engineering on ligand-receptor interaction. (A) Comparison of the ${ }^{\mathrm{A} 384 \mathrm{~V}} \mathrm{COI} 1$ (green)/COR/JAZ1 (orange) complex (left) and the ${ }^{\mathrm{A} 384 \mathrm{~V}} \mathrm{COI} 1 / \mathrm{JA}-I l e$ complex (right) at the ligand binding pocket; (B) comparison of the PYR1 (brown)/ABA/HAB1 (green) complex (left) and the holed PYR1/mandipropamid complex (right) at the ligand binding pocket; (C) comparison of the

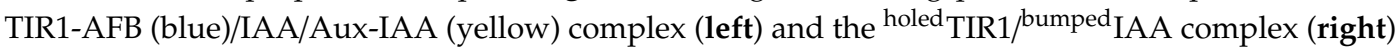
at the ligand binding pocket. The structures and surfaces were modeled, docked, and rendered using MOE from (A) 3OGM, 3OGL; (B) 3QN1, 4WGD; and (C) 2P1Q, respectively. The ligand molecules are highlighted in sphere, and mutated residues are highlighted in either sphere or ball-and-stick, Red ball is oxygen and blue ball is nitrogen.

\section{Other Chemicals Involved in the Tuned Regulation of Jasmonate Signaling}

The discovery of new COI1-JAZ coreceptor ligands was a landmark in jasmonate chemical biology. Some of these ligands are involved in the tuned activation of jasmonate signaling and are a possible basis for the development of chemical tools regulating the jasmonate signaling (Figure 5).

Amino acid conjugates of JA are known as conventionally-tuned jasmonates (Figure 5A). JA-Trp conjugate causes agravitropic root growth in seedlings of $A$. thaliana in a COI1-independent manner [57]. Xie's group reported that the amino acid conjugates, JA-Leu, JA-Val, JA-Met, and JA-Ala, function as endogenous jasmonates as well as JA-Ile [58]. This result will be useful for further molecular design of COI1-JAZ agonists, the spatial limitations of the ligand-binding pocket of COI1 having been demonstrated - a finding supported by the molecular docking study by Ueda' s group [59].

JA-Ile-macrolactone is an artificial jasmonate prepared by Boland's group (Figure 5B) [60,61] and found to upregulate the defense response of the wild tobacco Nicotiana attenuate without affecting its growth. This uncoupling of growth and defense is also reported to depend on Nicotiana COI1. A similar phenotype was also reported by Howe's group in Arabidopsis mutant impaired in quintuple JAZs in addition to $P h y B$ [62]. The upregulation of the defense response against herbivores without growth inhibition was observed in the $j a z Q$ phyB mutant; the growth inhibition was found to be suppressed 
by jasmonate-gibberellin signaling crosstalk. One hypothesis is that JA-Ile-macrolactone affects both COI1-JAZ and the crosstalk between jasmonate and gibberellin, resulting in the uncoupling of growth and defense in Nicotiana attenuata.

A

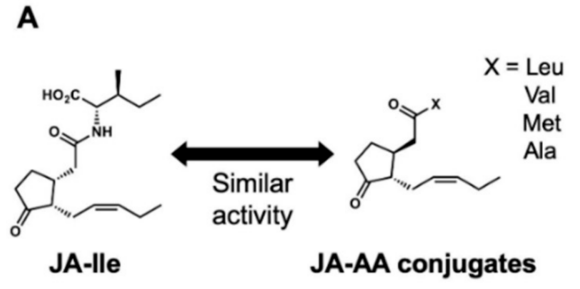

B

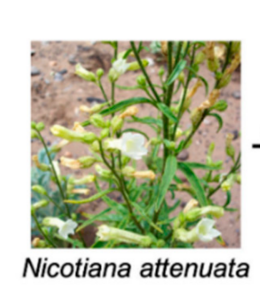

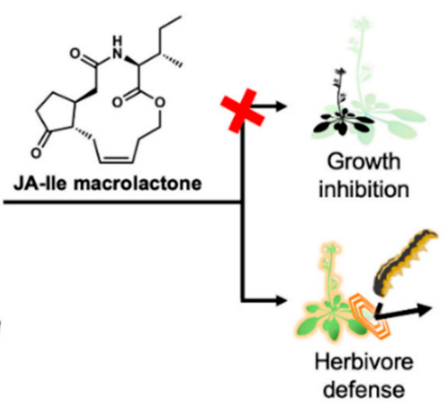

C

Moderately active
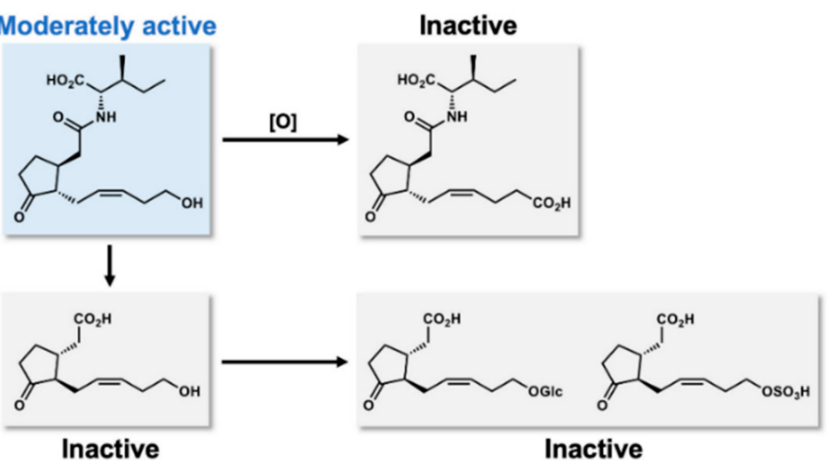

Figure 5. Other chemicals involved in the tuned regulation of jasmonate signaling. (A) JA amino acid conjugates with JA-Ile like activity; (B) JA-Ile macrolactone uncouples growth-defense trade-off; and $(\mathbf{C})$ known metabolites of JA-Ile and their JA-Ile like activity, red " $\times$ " means "without causing growth inhibition.

12-Hydroxy JA-Ile (12-OH-JA-Ile) is an inactivated derivative of JA-Ile (Figure 5C) [63,64]. Hydroxylation of JA-Ile by CYP94 monooxygenases (CYP94B1/B3/C1) occurs as a late response of jasmonate signaling to lower the endogenous concentration of bioactive JA-Ile and suppress jasmonate responses [65-67]. Koo's and Solano's groups revealed that 12-OH-JA-Ile can be perceived by COI1-JAZ coreceptor with weak/moderate affinity in Arabidopsis and is expected to be involved in some of jasmonate responses [68,69]. Interestingly, 12-OH-JA-Ile may be selective for some JAZ subtypes and be involved in the regulation of selected jasmonate response. Considering that 12-OH-JA-Ile accumulates 10-fold higher levels than JA-Ile at a later stage and the high concentration level continues more than $8 \mathrm{~h}$, the moderate and biased JAZ degradation by 12-OH-JA-Ile may fine-tune late jasmonate responses. 12-OH-JA-Ile can be further converted to 12-COOH-JA-Ile by CYP94C1 [67], 12-OH-JA by

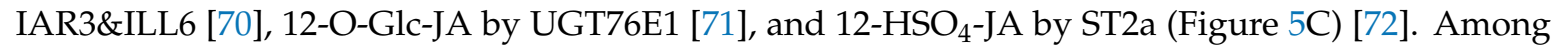
them, only 12-O-Glc-JA is biologically active in a plant, causing leaf-folding movement of Samanea saman in COI1-independent manner [73]. However, these metabolites have no affinity with COI1-JAZ coreceptor, suggesting that 12-OH-JA-Ile may be the possible component of metabolic regulation of jasmonate response.

One particularly intriguing research topic in plant hormone biology is the ancestral origin of hormone-receptor pair (Figure 6) [74]. The genome sequence of a bryophyte Marchantia polymorpha revealed the unique nature of this ancestral plant [75]. No genetic redundancy was found for jasmonate signaling components in M. polymorpha: one MpCOI1 and one MpJAZ. Solano's group focused on the jasmonate signaling in $M$. polymorpha, the redundant-free nature of which is convenient for genetic analyses of jasmonate signaling [51,52]. However, the unique $M p C O I 1-M p J A Z$ coreceptor pair cannot perceive JA-Ile/COR, and the endogenous ligand is confirmed cis/iso-dinor-OPDA [76]. This is the result of unique ligand-receptor coevolution. A single point mutation in $\mathrm{M} p \mathrm{COI} 1$ causes this difference 
in ligand selectivity. Considering the high homology between MpJAZ and Arabidopsis JAZs belonging to Group V (JAZ3/4/9) [77], MpCOI1-cis/iso-dinor-OPDA complex might have selective affinity with Arabidopsis JAZs belonging to Group V.

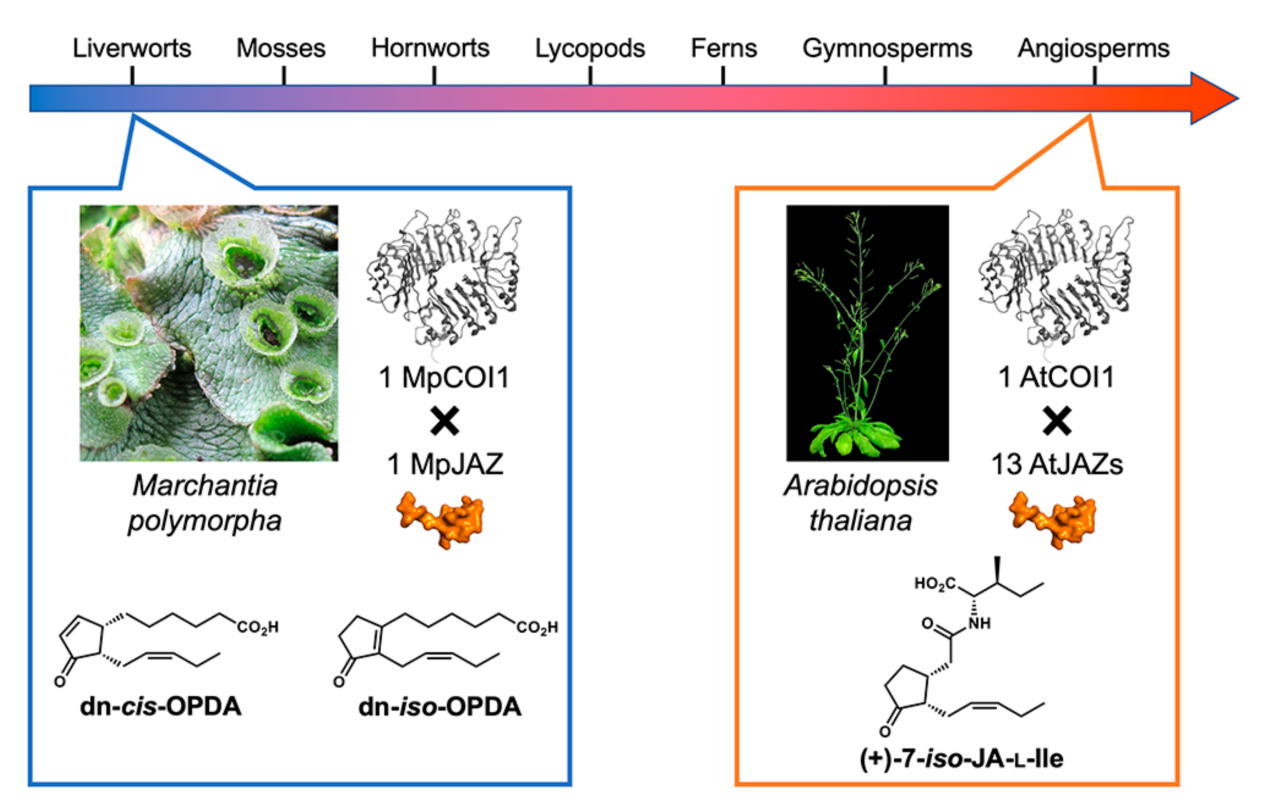

Figure 6. Ligand-receptor coevolution in jasmonate signaling.

\section{A Chemical Tool for Jasmonate Research from Chemical Library Screening}

Jarin-1, a selective inhibitor of JAR1 enzyme, is the sole successful example of the chemical library screening on jasmonate signaling (Figure 7) [78]. JAR1 is a key enzyme of jasmonate signaling that conjugates (+)-7-iso-jasmonic acid to L-isoleucine to provide JA-Ile. Jarin-1 efficiently suppressed this process of JA-Ile biosynthesis and selectively impaired multiple jasmonate responses in Arabidopsis thaliana.

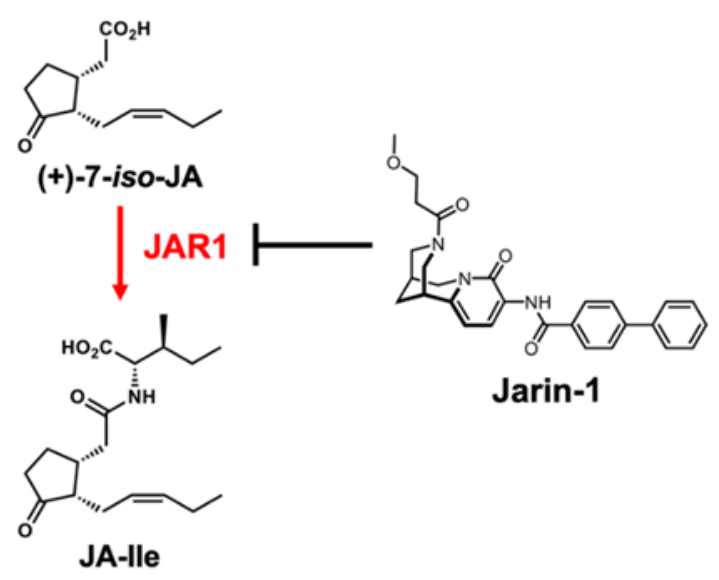

Figure 7. Jarin-1: the sole inhibitor of JAR1.

\section{Possible Design of Chemical Tools in Non-Arabidopsis Plants}

Some of the abovementioned chemical tools have been validated in non-Arabidopsis plants, but their future application is contingent upon the tuning of their chemical structures for the corresponding orthologs of Arabidopsis COI1-JAZs. However, no crystal structure of such orthologs exists-the COI1-JAZ1-COR/JA-Ile complex is the only exact structure reported so far. Recently, however, in silico homology modeling of orthologous COI1-JAZ with ligands has been reported. Boland's 
group demonstrated the first application of homology modeling and docking studies on the possible structure of lima bean PlCOI1-PlJAZ and a coronalon derivative [79]. Figueroa's group also reported woodland strawberry FvCOI1-FvJAZ1 and JA-Ile [80]. Further development in such studies is expected to inform the design of agonists and antagonists of orthologous COI1-JAZ coreceptor system for non-Arabidopsis plants.

\section{Conclusions}

The development of chemical tools for the regulation of plant hormone signaling is a promising field of research, and significant advances have been made in the past two decades. However, the tools developed to date are limited to the upregulation of plant defense responses against necrotrophic pathogen or insect attack, and although these are important, more versatile tools such as those that are able to improve the efficiency of plant growth are highly desirable. One research priority is a tool that is able to upregulate [79] secondary metabolite production in medicinal plants without concomitant growth inhibition [81,82], and recent studies have revealed the relationship between jasmonate signaling and transcription factors $(\mathrm{TFs})$, which govern the biosynthetic genes of secondary metabolites $[83,84]$. Thus, chemical control of individual TF or JAZs in the upstream pathway could be an efficient strategy. Progress in the development of novel chemical tools will advance the tuning and regulation of jasmonate responses [85].

Funding: This work was supported by a Grant-in-Aid for Scientific Research for MU from MEXT, Japan (nos. 26282207, 18KK0162, 17H06407, and 17H00885), JSPS A3 Foresight Program (MU), and JSPS Core-to-Core Program Asian Chemical Biology Initiative (MU).

Conflicts of Interest: The authors declare no conflict of interest. The funders had no role in the design of the study; in the collection, analyses, or interpretation of data; in the writing of the manuscript, or in the decision to publish the results.

\section{References}

1. Umehara, M.; Hanada, A.; Yoshida, S.; Akiyama, K.; Arite, T.; Takeda-Kamiya, N.; Magome, H.; Kamiya, Y.; Shirasu, K.; Yoneyama, K.; et al. Inhibition of shoot branching by new terpenoid plant hormones. Nature 2008, 455, 195-200. [CrossRef] [PubMed]

2. Gomez-Roldan, V.; Fermas, S.; Brewer, P.B.; Puech-Pages, V.; Dun, E.A.; Pillot, J.P.; Letisse, F.; Matusova, R.; Danoun, S.; Portais, J.C.; et al. Strigolactone inhibition of shoot branching. Nature 2008, 455, 189-194. [CrossRef] [PubMed]

3. Ohyama, K.; Ogawa, M.; Matsubayashi, Y. Identification of a biologically active, small, secreted peptide in Arabidopsis by in silico gene screening, followed by LC-MS-based structure analysis. Plant J. 2008, 55, 152-160. [CrossRef] [PubMed]

4. Demole, E.; Lederer, E.; Mercier, D. Isolement et détermination de la structure du jasmonate de méthyle, constituant odorant caractéristique de l'essence de jasmin. Helv. Chim. Acta 1962, 45. [CrossRef]

5. Dathe, W.; Ronsch, H.; Preiss, A.; Schade, W.; Sembdner, G.; Schreiber, K. Endogenous plant hormones of the broad bean, Vicia faba L. (-)-jasmonic acid, a plant growth inhibitor in pericarp. Planta 1981, 153, 530-535. [CrossRef]

6. Wasternack, C. How Jasmonates Earned their Laurels: Past and Present. J. Plant Growth Regul. 2015, 34, 761-794. [CrossRef]

7. Wasternack, C.; Song, S. Jasmonates: Biosynthesis, metabolism, and signaling by proteins activating and repressing transcription. J. Exp. Bot. 2017, 68, 1303-1321. [CrossRef]

8. Wasternack, C.; Hause, B. Jasmonates: Biosynthesis, perception, signal transduction and action in plant stress response, growth and development. An update to the 2007 review in Annals of Botany. Ann. Bot. 2013, 111, 1021-1058. [CrossRef]

9. Acosta, I.F.; Laparra, H.; Romero, S.P.; Schmelz, E.; Hamberg, M.; Mottinger, J.P.; Moreno, M.A.; Dellaporta, S.L. Tasselseed1 is a Lipoxygenase Affecting Jasmonic Acid Signaling in Sex Determination of Maize. Science 2009, 323, 262-265. [CrossRef] 
10. Lunde, C.; Kimberlin, A.; Leiboff, S.; Koo, A.J.; Hake, S. Tasselseed5 overexpresses a wound-inducible enzyme, ZmCYP94B1, that affects jasmonate catabolism, sex determination, and plant architecture in maize. Commun. Biol. 2019, 2, 114. [CrossRef]

11. Chini, A.; Fonseca, S.; Fernandez, G.; Adie, B.; Chico, J.M.; Lorenzo, O.; Garcia-Casado, G.; Lopez-Vidriero, I.; Lozano, F.M.; Ponce, M.R.; et al. The JAZ family of repressors is the missing link in jasmonate signalling. Nature 2007, 448, 666-671. [CrossRef] [PubMed]

12. Thines, B.; Katsir, L.; Melotto, M.; Niu, Y.; Mandaokar, A.; Liu, G.; Nomura, K.; He, S.Y.; Howe, G.A.; Browse, J. JAZ repressor proteins are targets of the $\mathrm{SCF}(\mathrm{COI} 1)$ complex during jasmonate signalling. Nature 2007, 448, 661-665. [CrossRef] [PubMed]

13. Yan, Y.; Stolz, S.; Chetelat, A.; Reymond, P.; Pagni, M.; Dubugnon, L.; Farmer, E.E. A downstream mediator in the growth repression limb of the jasmonate pathway. Plant Cell 2007, 19, 2470-2483. [CrossRef] [PubMed]

14. Staswick, P.E.; Tiryaki, I. The oxylipin signal jasmonic acid is activated by an enzyme that conjugates it to isoleucine in Arabidopsis. Plant Cell 2004, 16, 2117-2127. [CrossRef]

15. Fonseca, S.; Chini, A.; Hamberg, M.; Adie, B.; Porzel, A.; Kramell, R.; Miersch, O.; Wasternack, C.; Solano, R. (+)-7-iso-Jasmonoyl-L-isoleucine is the endogenous bioactive jasmonate. Nat. Chem. Biol. 2009, 5, 344-350. [CrossRef]

16. Shan, X.; Yan, J.; Xie, D. Comparison of phytohormone signaling mechanisms. Curr. Opin. Plant Biol. 2012, 15, 84-91. [CrossRef]

17. Lumba, S.; Cutler, S.; McCourt, P. Plant nuclear hormone receptors: A role for small molecules in protein-protein interactions. Annu. Rev. Cell Dev. Biol. 2010, 26, 445-469. [CrossRef]

18. Hayashi, K.; Neve, J.; Hirose, M.; Kuboki, A.; Shimada, Y.; Kepinski, S.; Nozaki, H. Rational Design of an Auxin Antagonist of the SCF(TIR1) Auxin Receptor Complex. ACS Chem. Biol. 2012, 7, 590-598. [CrossRef]

19. Hayashi, K.; Tan, X.; Zheng, N.; Hatate, T.; Kimura, Y.; Kepinski, S.; Nozaki, H. Small-molecule agonists and antagonists of F-box protein-substrate interactions in auxin perception and signaling. Proc. Natl. Acad. Sci. USA 2008, 105, 5632-5637. [CrossRef]

20. Ichihara, A.; Shiraishi, K.; Sato, H.; Sakamura, S.; Nishiyama, K.; Sakai, R.; Furusaki, A.; Matsumoto, T. The structure of coronatine. J. Am. Chem. Soc. 1977, 99, 636-637. [CrossRef]

21. Koda, Y.; Takahashi, K.; Kikuta, Y.; Greulich, F.; Toshima, H.; Ichihara, A. Similarities of the biological activities of coronatine and coronafacic acid to those of jasmonic acid. Phytochemistry 1996, 41, 93-96. [CrossRef]

22. Sheard, L.B.; Tan, X.; Mao, H.; Withers, J.; Ben-Nissan, G.; Hinds, T.R.; Kobayashi, Y.; Hsu, F.F.; Sharon, M.; Browse, J.; et al. Jasmonate perception by inositol-phosphate-potentiated COI1-JAZ coreceptor. Nature 2010, 468, 400-405. [CrossRef] [PubMed]

23. Xie, D.X.; Feys, B.F.; James, S.; Nieto-Rostro, M.; Turner, J.G. COI1: An Arabidopsis gene required for jasmonate-regulated defense and fertility. Science 1998, 280, 1091-1094. [CrossRef] [PubMed]

24. Littleson, M.M.; Baker, C.M.; Dalencon, A.J.; Frye, E.C.; Jamieson, C.; Kennedy, A.R.; Ling, K.B.; McLachlan, M.M.; Montgomery, M.G.; Russell, C.J.; et al. Scalable total synthesis and comprehensive structure-activity relationship studies of the phytotoxin coronatine. Nat. Commun. 2018, 9, 1105. [CrossRef] [PubMed]

25. Littleson, M.M.; Russell, C.J.; Frye, E.C.; Ling, K.B.; Jamieson, C.; Watson, A.J.B. Synthetic Approaches to Coronafacic Acid, Coronamic Acid, and Coronatine. Synthesis 2016, 48, 3429-3448. [CrossRef]

26. Kato, N.; Miyagawa, S.; Nomoto, H.; Nakayama, M.; Iwashita, M.; Ueda, M. A Scalable Synthesis of (+)-Coronafacic Acid. Chirality 2020, 32. in press. [CrossRef]

27. Schüler, G.; Mithöfer, A.; Baldwin, I.T.; Berger, S.; Ebel, J.; Santos, J.G.; Herrmann, G.; Hölscher, D.; Kramell, R.; Kutchan, T.M. Coronalon: A powerful tool in plant stress physiology. FEBS Lett. 2004, 563, 17-22. [CrossRef]

28. Lauchli, R.; Boland, W. Indanoyl amino acid conjugates: Tunable elicitors of plant secondary metabolism. Chem. Rec. 2003, 3, 12-21. [CrossRef]

29. Chini, A.; Gimenez-Ibanez, S.; Goossens, A.; Solano, R. Redundancy and specificity in jasmonate signalling. Curr. Opin. Plant Biol. 2016, 33, 147-156. [CrossRef]

30. Dejonghe, W.; Russinova, E. Plant Chemical Genetics: From Phenotype-Based Screens to Synthetic Biology. Plant Physiol. 2017, 174, 5-20. [CrossRef]

31. Shyu, C.; Figueroa, P.; Depew, C.L.; Cooke, T.F.; Sheard, L.B.; Moreno, J.E.; Katsir, L.; Zheng, N.; Browse, J.; Howe, G.A. JAZ8 lacks a canonical degron and has an EAR motif that mediates transcriptional repression of jasmonate responses in Arabidopsis. Plant Cell 2012, 24, 536-550. [CrossRef] [PubMed] 
32. Thireault, C.; Shyu, C.; Yoshida, Y.; St Aubin, B.; Campos, M.L.; Howe, G.A. Repression of jasmonate signaling by a non-TIFY JAZ protein in Arabidopsis. Plant J. 2015, 82, 669-679. [CrossRef] [PubMed]

33. Garrido-Bigotes, A.; Valenzuela-Riffo, F.; Figueroa, C.R. Evolutionary Analysis of JAZ Proteins in Plants: An Approach in Search of the Ancestral Sequence. Int. J. Mol. Sci. 2019, 20, 5060. [CrossRef] [PubMed]

34. Pauwels, L.; Goossens, A. The JAZ proteins: A crucial interface in the jasmonate signaling cascade. Plant Cell 2011, 23, 3089-3100. [CrossRef]

35. Kazan, K.; Manners, J.M. JAZ repressors and the orchestration of phytohormone crosstalk. Trends Plant Sci. 2012, 17, 22-31. [CrossRef]

36. Dharmasiri, N.; Dharmasiri, S.; Estelle, M. The F-box protein TIR1 is an auxin receptor. Nature 2005, 435, 441-445. [CrossRef]

37. Monte, I.; Hamberg, M.; Chini, A.; Gimenez-Ibanez, S.; Garcia-Casado, G.; Porzel, A.; Pazos, F.; Boter, M.; Solano, R. Rational design of a ligand-based antagonist of jasmonate perception. Nat. Chem. Biol. 2014, 10, 671-676. [CrossRef]

38. Takeuchi, J.; Okamoto, M.; Akiyama, T.; Muto, T.; Yajima, S.; Sue, M.; Seo, M.; Kanno, Y.; Kamo, T.; Endo, A.; et al. Designed abscisic acid analogs as antagonists of PYL-PP2C receptor interactions. Nat. Chem. Biol. 2014, 10, 477-482. [CrossRef]

39. Helander, J.D.; Vaidya, A.S.; Cutler, S.R. Chemical manipulation of plant water use. Bioorg. Med. Chem. 2016, 24, 493-500. [CrossRef]

40. Park, S.-Y.; Fung, P.; Nishimura, N.; Jensen, D.R.; Fujii, H.; Zhao, Y.; Lumba, S.; Santiago, J.; Rodrigues, A.; Chow, T.-f.F.; et al. Abscisic Acid Inhibits Type 2C Protein Phosphatases via the PYR/PYL Family of START Proteins. Science 2009, 324, 1068-1071. [CrossRef]

41. Zhao, Y.; Chow, T.F.; Puckrin, R.S.; Alfred, S.E.; Korir, A.K.; Larive, C.K.; Cutler, S.R. Chemical genetic interrogation of natural variation uncovers a molecule that is glycoactivated. Nat. Chem. Biol. 2007, 3, 716-721. [CrossRef] [PubMed]

42. Okamoto, M.; Peterson, F.C.; Defries, A.; Park, S.Y.; Endo, A.; Nambara, E.; Volkman, B.F.; Cutler, S.R. Activation of dimeric ABA receptors elicits guard cell closure, ABA-regulated gene expression, and drought tolerance. Proc. Natl. Acad. Sci. USA 2013, 110, 12132-12137. [CrossRef]

43. Vaidya, A.S.; Peterson, F.C.; Yarmolinsky, D.; Merilo, E.; Verstraeten, I.; Park, S.Y.; Elzinga, D.; Kaundal, A.; Helander, J.; Lozano-Juste, J.; et al. A Rationally Designed Agonist Defines Subfamily IIIA Abscisic Acid Receptors As Critical Targets for Manipulating Transpiration. ACS Chem. Biol. 2017, 12, 2842-2848. [CrossRef]

44. Vaidya, A.S.; Helander, J.D.M.; Peterson, F.C.; Elzinga, D.; Dejonghe, W.; Kaundal, A.; Park, S.Y.; Xing, Z.N.; Mega, R.; Takeuchi, J.; et al. Dynamic control of plant water use using designed ABA receptor agonists. Science 2019, 366, eaaw8848. [CrossRef]

45. Uraguchi, D.; Kuwata, K.; Hijikata, Y.; Yamaguchi, R.; Imaizumi, H.; AM, S.; Rakers, C.; Mori, N.; Akiyama, K.; Irle, S.; et al. A femtomolar-range suicide germination stimulant for the parasitic plant Striga hermonthica. Science 2018, 362, 1301-1305. [CrossRef]

46. Takaoka, Y.; Iwahashi, M.; Chini, A.; Saito, H.; Ishimaru, Y.; Egoshi, S.; Kato, N.; Tanaka, M.; Bashir, K.; Seki, M.; et al. A rationally designed JAZ subtype-selective agonist of jasmonate perception. Nat. Commun. 2018, 9, 3654. [CrossRef]

47. Yan, J.; Zhang, C.; Gu, M.; Bai, Z.; Zhang, W.; Qi, T.; Cheng, Z.; Peng, W.; Luo, H.; Nan, F.; et al. The Arabidopsis CORONATINE INSENSITIVE1 protein is a jasmonate receptor. Plant Cell 2009, 21, 2220-2236. [CrossRef]

48. Yan, J.; Yao, R.; Chen, L.; Li, S.; Gu, M.; Nan, F.; Xie, D. Dynamic Perception of Jasmonates by the F-Box Protein COI1. Mol. Plant 2018, 11, 1237-1247. [CrossRef]

49. Pieterse, C.M.; Van der Does, D.; Zamioudis, C.; Leon-Reyes, A.; Van Wees, S.C. Hormonal modulation of plant immunity. Annu. Rev. Cell Dev. Biol. 2012, 28, 489-521. [CrossRef]

50. Guo, Q.; Yoshida, Y.; Major, I.T.; Wang, K.; Sugimoto, K.; Kapali, G.; Havko, N.E.; Benning, C.; Howe, G.A. JAZ repressors of metabolic defense promote growth and reproductive fitness in Arabidopsis. Proc. Natl. Acad. Sci. USA 2018, 115, E10768-E10777. [CrossRef]

51. Monte, I.; FrancoZorrilla, J.M.; Garcia-Casado, G.; Zamarreno, A.M.; Garcia-Mina, J.M.; Nishihama, R.; Kohchi, T.; Solano, R. A single JAZ repressor controls the jasmonate pathway in Marchantia polymorpha. Mol. Plant 2018. [CrossRef] [PubMed] 
52. Gimenez-Ibanez, S.; Zamarreno, A.M.; Garcia-Mina, J.M.; Solano, R. An Evolutionarily Ancient Immune System Governs the Interactions between Pseudomonas syringae and an Early-Diverging Land Plant Lineage. Curr. Biol. 2019, 29, 2270-2281.e2274. [CrossRef]

53. Zhang, L.; Yao, J.; Withers, J.; Xin, X.F.; Banerjee, R.; Fariduddin, Q.; Nakamura, Y.; Nomura, K.; Howe, G.A.; Boland, W.; et al. Host target modification as a strategy to counter pathogen hijacking of the jasmonate hormone receptor. Proc. Natl. Acad. Sci. USA 2015, 112, 14354-14359. [CrossRef] [PubMed]

54. Park, S.Y.; Peterson, F.C.; Mosquna, A.; Yao, J.; Volkman, B.F.; Cutler, S.R. Agrochemical control of plant water use using engineered abscisic acid receptors. Nature 2015, 520, 545-548. [CrossRef] [PubMed]

55. Islam, K. The Bump-and-Hole Tactic: Expanding the Scope of Chemical Genetics. Cell Chem. Biol. 2018, 25, 1171-1184. [CrossRef] [PubMed]

56. Uchida, N.; Takahashi, K.; Iwasaki, R.; Yamada, R.; Yoshimura, M.; Endo, T.A.; Kimura, S.; Zhang, H.; Nomoto, M.; Tada, Y.; et al. Chemical hijacking of auxin signaling with an engineered auxin-TIR1 pair. Nat. Chem. Biol. 2018, 14, 299-305. [CrossRef]

57. Staswick, P.E. The Tryptophan Conjugates of Jasmonic and Indole-3-Acetic Acids Are Endogenous Auxin Inhibitors. Plant Physiol. 2009, 150, 1310-1321. [CrossRef]

58. Yan, J.; Li, S.; Gu, M.; Yao, R.; Li, Y.; Chen, J.; Yang, M.; Tong, J.; Xiao, L.; Nan, F.; et al. Endogenous Bioactive Jasmonate Is Composed of a Set of (+)-7-iso-JA-Amino Acid Conjugates. Plant Physiol. 2016, 172, $2154-2164$. [CrossRef]

59. Egoshi, S.; Takaoka, Y.; Saito, H.; Nukadzuka, Y.; Hayashi, K.; Ishimaru, Y.; Yamakoshi, H.; Dodo, K.; Sodeoka, M.; Ueda, M. Dual function of coronatine as a bacterial virulence factor against plants: Possible COI1-JAZ-independent role. RSC Adv. 2016, 6, 19404-19412. [CrossRef]

60. Jimenez-Aleman, G.H.; Machado, R.A.R.; Gorls, H.; Baldwin, I.T.; Boland, W. Synthesis, structural characterization and biological activity of two diastereomeric JA-Ile macrolactones. Org. Biomol. Chem. 2015, 13, 5885-5893. [CrossRef]

61. Jimenez-Aleman, G.H.; Machado, R.A.R.; Baldwin, I.T.; Boland, W. JA-Ile-macrolactones uncouple growth and defense in wild tobacco. Org. Biomol. Chem. 2017, 15, 3391-3395. [CrossRef] [PubMed]

62. Campos, M.L.; Yoshida, Y.; Major, I.T.; de Oliveira Ferreira, D.; Weraduwage, S.M.; Froehlich, J.E.; Johnson, B.F.; Kramer, D.M.; Jander, G.; Sharkey, T.D.; et al. Rewiring of jasmonate and phytochrome B signalling uncouples plant growth-defense tradeoffs. Nat. Commun. 2016, 7, 12570. [CrossRef] [PubMed]

63. Glauser, G.; Grata, E.; Dubugnon, L.; Rudaz, S.; Farmer, E.E.; Wolfender, J.L. Spatial and temporal dynamics of jasmonate synthesis and accumulation in Arabidopsis in response to wounding. J. Biol. Chem. 2008, 283, 16400-16407. [CrossRef]

64. Miersch, O.; Neumerkel, J.; Dippe, M.; Stenzel, I.; Wasternack, C. Hydroxylated jasmonates are commonly occurring metabolites of jasmonic acid and contribute to a partial switch-off in jasmonate signaling. New Phytol. 2008, 177, 114-127. [CrossRef]

65. Kitaoka, N.; Matsubara, T.; Sato, M.; Takahashi, K.; Wakuta, S.; Kawaide, H.; Matsui, H.; Nabeta, K.; Matsuura, H. Arabidopsis CYP94B3 encodes jasmonyl-L-isoleucine 12-hydroxylase, a key enzyme in the oxidative catabolism of jasmonate. Plant Cell Physiol. 2011, 52, 1757-1765. [CrossRef]

66. Koo, A.J.; Cooke, T.F.; Howe, G.A. Cytochrome P450 CYP94B3 mediates catabolism and inactivation of the plant hormone jasmonoyl-L-isoleucine. Proc. Natl. Acad. Sci. USA 2011, 108, 9298-9303. [CrossRef]

67. Heitz, T.; Widemann, E.; Lugan, R.; Miesch, L.; Ullmann, P.; Desaubry, L.; Holder, E.; Grausem, B.; Kandel, S.; Miesch, M.; et al. Cytochromes P450 CYP94C1 and CYP94B3 catalyze two successive oxidation steps of plant hormone Jasmonoyl-isoleucine for catabolic turnover. J. Biol. Chem. 2012, 287, 6296-6306. [CrossRef]

68. Poudel, A.N.; Holtsclaw, R.E.; Kimberlin, A.; Sen, S.; Zeng, S.; Joshi, T.; Lei, Z.; Sumner, L.W.; Singh, K.; Matsuura, H.; et al. 12-Hydroxy-jasmonoyl-L-isoleucine is an active jasmonate that signals through CORONATINE INSENSITIVE 1 and contributes to the wound response in Arabidopsis. Plant Cell Physiol. 2019. [CrossRef]

69. Jimenez-Aleman, G.H.; Almeida-Trapp, M.; Fernandez-Barbero, G.; Gimenez-Ibanez, S.; Reichelt, M.; Vadassery, J.; Mithofer, A.; Caballero, J.; Boland, W.; Solano, R. Omega hydroxylated JA-Ile is an endogenous bioactive jasmonate that signals through the canonical jasmonate signaling pathway. Biochim. Biophys. Acta Mol. Cell Biol. Lipids 2019, 1864, 158520. [CrossRef] 
70. Widemann, E.; Miesch, L.; Lugan, R.; Holder, E.; Heinrich, C.; Aubert, Y.; Miesch, M.; Pinot, F.; Heitz, T. The amidohydrolases IAR3 and ILL6 contribute to jasmonoyl-isoleucine hormone turnover and generate 12-hydroxyjasmonic acid upon wounding in Arabidopsis leaves. J. Biol. Chem. 2013, 288, 31701-31714. [CrossRef]

71. Haroth, S.; Feussner, K.; Kelly, A.A.; Zienkiewicz, K.; Shaikhqasem, A.; Herrfurth, C.; Feussner, I. The glycosyltransferase UGT76E1 significantly contributes to 12-O-glucopyranosyl-jasmonic acid formation in wounded Arabidopsis thaliana leaves. J. Biol. Chem. 2019, 294, 9858-9872. [CrossRef] [PubMed]

72. Gidda, S.K.; Miersch, O.; Levitin, A.; Schmidt, J.; Wasternack, C.; Varin, L. Biochemical and molecular characterization of a hydroxyjasmonate sulfotransferase from Arabidopsis thaliana. J. Biol. Chem. 2003, 278, 17895-17900. [CrossRef] [PubMed]

73. Nakamura, Y.; Mithofer, A.; Kombrink, E.; Boland, W.; Hamamoto, S.; Uozumi, N.; Tohma, K.; Ueda, M. 12-hydroxyjasmonic acid glucoside is a COI1-JAZ-independent activator of leaf-closing movement in Samanea saman. Plant Physiol. 2011, 155, 1226-1236. [CrossRef] [PubMed]

74. Miyazaki, S.; Hara, M.; Ito, S.; Tanaka, K.; Asami, T.; Hayashi, K.I.; Kawaide, H.; Nakajima, M. An Ancestral Gibberellin in a Moss Physcomitrella patens. Mol. Plant 2018, 11, 1097-1100. [CrossRef]

75. Bowman, J.L.; Kohchi, T.; Yamato, K.T.; Jenkins, J.; Shu, S.Q.; Ishizaki, K.; Yamaoka, S.; Nishihama, R.; Nakamura, Y.; Berger, F.; et al. Insights into Land Plant Evolution Garnered from the Marchantia polymorpha Genome. Cell 2017, 171, 287-304. [CrossRef]

76. Monte, I.; Ishida, S.; Zamarreno, A.M.; Hamberg, M.; FrancoZorrilla, J.M.; Garcia-Casado, G.; Gouhier-Darimont, C.; Reymond, P.; Takahashi, K.; Garcia-Mina, J.M.; et al. Ligand-receptor coevolution shaped the jasmonate pathway in land plants. Nat. Chem. Biol. 2018, 14, 480-488. [CrossRef]

77. Bai, Y.; Meng, Y.; Huang, D.; Qi, Y.; Chen, M. Origin and evolutionary analysis of the plant-specific TIFY transcription factor family. Genomics 2011, 98, 128-136. [CrossRef]

78. Meesters, C.; Monig, T.; Oeljeklaus, J.; Krahn, D.; Westfall, C.S.; Hause, B.; Jez, J.M.; Kaiser, M.; Kombrink, E. A chemical inhibitor of jasmonate signaling targets JAR1 in Arabidopsis thaliana. Nat. Chem. Biol. 2014, 10, 830-836. [CrossRef]

79. Nakamura, Y.; Paetz, C.; Brandt, W.; David, A.; Rendon-Anaya, M.; Herrera-Estrella, A.; Mithofer, A.; Boland, W. Synthesis of 6-substituted 1-oxoindanoyl isoleucine conjugates and modeling studies with the COI1-JAZ coreceptor complex of lima bean. J. Chem. Ecol. 2014, 40, 687-699. [CrossRef]

80. Valenzuela-Riffo, F.; Garrido-Bigotes, A.; Figueroa, P.M.; Morales-Quintana, L.; Figueroa, C.R. Structural analysis of the woodland strawberry COI1-JAZ1 coreceptor for the plant hormone jasmonoyl-isoleucine. J. Mol. Graph. Model. 2018, 85, 250-261. [CrossRef]

81. Wurtzel, E.T.; Kutchan, T.M. Plant metabolism, the diverse chemistry set of the future. Science 2016, 353, 1232-1236. [CrossRef]

82. Deng, X.; Guo, D.; Yang, S.; Shi, M.; Chao, J.; Li, H.; Peng, S.; Tian, W. Jasmonate signalling in the regulation of rubber biosynthesis in laticifer cells of rubber tree, Hevea brasiliensis. J. Exp. Bot. 2018, 69, 3559-3571. [CrossRef]

83. Wasternack, C.; Strnad, M. Jasmonates are signals in the biosynthesis of secondary metabolites-Pathways, transcription factors and applied aspects-A brief review. New Biotechnol. 2019, 48, 1-11. [CrossRef] [PubMed]

84. De Geyter, N.; Gholami, A.; Goormachtig, S.; Goossens, A. Transcriptional machineries in jasmonate-elicited plant secondary metabolism. Trends Plant Sci. 2012, 17, 349-359. [CrossRef] [PubMed]

85. Takaoka, Y.; Nagumo, K.; Azizah, I.N.; Oura, S.; Iwahashi, M.; Kato, N.; Ueda, M. A comprehensive in vitro fluorescence anisotropy assay system for screening ligands of the jasmonate COI1-JAZ coreceptor in plants. J. Biol. Chem. 2019, 294, 5074-5081. [CrossRef] [PubMed]

(C) 2020 by the authors. Licensee MDPI, Basel, Switzerland. This article is an open access article distributed under the terms and conditions of the Creative Commons Attribution (CC BY) license (http://creativecommons.org/licenses/by/4.0/). 